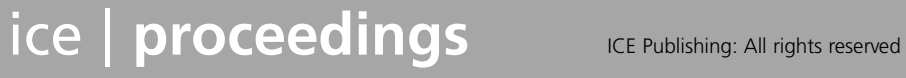

\section{Discussion: Stop-end method for the panel connection of cut-off walls}

\section{Huifang Song}

Lecturer, State Key Laboratory of Hydraulic Engineering Simulation and Safety, Tianjin University, Tianjin, China

\section{Wei Cui}

Associate Professor, State Key Laboratory of Hydraulic Engineering Simulation and Safety, Tianjin University, Tianjin, China

\section{Nigel Somers}

Chief Civil Engineer, Multiconsult UK Ltd, Ashford, UK

\section{Contribution by N. Somers}

The authors (Song and Cui, 2015) are to be congratulated on the achievement of such a deep cut-off wall. My reading of the paper raised the need for a minor clarification and some additional information that would be of interest.

(a) Regarding the clarification, Figures 6, 7 and 8 and explanations within the text refer to extraction forces, self-weight (of pipe) and various frictional forces with units of MPa, which is the usual unit for pressure. Can the authors clarify whether the units of measurement should be MN?

(b) Regarding additional information, can the authors advise on the typical and maximum time periods between the casting of primary concrete panels and secondary concrete panels during installation of the cut-off wall?

(c) Finally, can the authors advise on the accuracy of the panels in terms of variation from vertical (out-of-plane) of the panel and how this variation affected the joint formation, particularly close to the bottom of the wall?

\section{Authors' reply}

The authors thank the discusser for the questions raised on the paper.

(a) Regarding clarification of the units for force, the monitoring data obtained from the hydraulic jack were pressures in units of $\mathrm{MPa}$, so the units are given as $\mathrm{MPa}$ in the text. The relationship between the hydraulic jack pressure and the extraction force can be obtained from $F=0 \cdot 15 P$ since the active area of the piston of hydraulic jack was $0 \cdot 15 \mathrm{~m}^{2}$.

(b) Regarding the time period between casting the primary and secondary concrete panels, this time period cannot be prescribed as it depends on the depth of the cut-off wall, the construction conditions, climate, geology and so on. Generally, the secondary trench should be constructed within $24 \mathrm{~h}$ after completion of the primary panels, and the concrete of the secondary panels should be poured within $4 \mathrm{~h}$ after excavation of the secondary trench.

(c) Regarding the accuracy of the panels in terms of deviation of the panels from the vertical (out-of-plane), based on the monitoring results in the Pangduo project, the deviation from the vertical (along the wall axis) should not exceed 0.03 radians (i.e. $1 \cdot 7^{\circ}$ ), so that the horizontal deviation from the vertical at the level of the river at a depth of $15 \mathrm{~m}$ should be less than $450 \mathrm{~mm}$.

\section{REFERENCES}

Song $\mathrm{H}$ and Cui W (2015) Stop-end method for the panel connection of cut-off walls. Proceedings of the Institution of Civil Engineers - Geotechnical Engineering 168(5): 457-468, http://dx.doi.org/10.1680/geng.14.00086. 